Tropical Journal of Pharmaceutical Research June 2015; 14 (6): 1029-1034

ISSN: $1596-5996$ (print); 1596-9827 (electronic)

(C) Pharmacotherapy Group, Faculty of Pharmacy, University of Benin, Benin City, 300001 Nigeria.

All rights reserved.

Available online at http://www.tjpr.org

Original Research Article

http://dx.doi.org/10.4314/tjpr.v14i6.13

\title{
Phytochemical Screening and Hepatoprotective Effect of Alhagi maurorum Boiss (Leguminosae) Against Paracetamol-Induced Hepatotoxicity in Rabbits
}

\author{
Jalil Ur Rehman ${ }^{1}$, Naveed Akhtar ${ }^{2}$, Muhammad Younus Khan ${ }^{2}$, Khalil Ahmad ${ }^{1}$, \\ Mukhtiar Ahmad', Sabira Sultana ${ }^{1}$, Hafiz Muhammad Asif ${ }^{2 *}$ \\ ${ }^{1}$ University College of Conventional Medicine, Faculty of Pharmacy \& Alternative Medicine, The Islamia University of \\ Bahawalpur, '2Department of Pharmacy, Faculty of Pharmacy \& Alternative Medicine, The Islamia University of Bahawalpur, \\ ${ }^{3}$ Department of Eastern Medicine \& Surgery, Faculty of Medical \& Health Sciences, The University of Poonch, Rawalakot, AJ\& \\ K, Pakistan
}

*For correspondence: Email: doctor.asif101@gmail.com; Tel: +92 3346911256

Received: 6 October 2014

Revised accepted: 29 April 2015

\begin{abstract}
Purpose: To evaluate the hepatoprotective activity of aqueous-ethanol (30:70 \%) extract of Alhagi maurorum Boiss. (Leguminosae) whole plant against paracetamol-induced liver injury in experimental rabbits.

Methods: Aqueous-ethanol extract of Alhagi maurorum at doses of $250 \mathrm{mg} / \mathrm{kg}$ and $500 \mathrm{mg} / \mathrm{kg}$ body weight, p.o., was administered for 7 days in paracetamol (2 gm/kg, s.c.) intoxicated rabbits and compared with silymarine (50 mg/kg, p.o.)-treated rabbits. Biochemical parameters, alkaline phosphatase (ALP), serum glutamic oxalacetic transaminase (SGOT), serum glutamic pyruvic transaminase (SGPT) and total bilirubin (TB) levels were recorded to investigate the degree of improvement in the conditions of the rabbits. The liver was removed, washed with normal saline and preserved in $10 \%$ formalin and used in histopathological studies of hepatic architecture by microscopy. Phytochemical screening of the extract was also carried out.

Results: The levels of biochemical parameters were increased in paracetamol intoxicated rabbits when compared with the normal group. The extract, at doses of 250 and $500 \mathrm{mg} / \mathrm{kg}$, exhibited significant $(p<$ 0.001) reduction in biochemical parameters (ALP, SGOT, SGPT and TB). Hepatoprotective activity was also confirmed by histopathological findings. Furthermore, the phytochemical profile of the extract revealed the presence of tannins, alkaloids, saponins and flavonoids.

Conclusion: These results suggest that Alhagi maurorum extract possesses significant hepatoprotective effect against paracetamol-induced hepatotoxicity and this may be due to the presence of flavonoids and tannins.
\end{abstract}

Keywords: Alhagi maurorum, Hepatoprotective, Paracetamol, Silymarin, Histopathology

Tropical Journal of Pharmaceutical Research is indexed by Science Citation Index (SciSearch), Scopus, International Pharmaceutical Abstract, Chemical Abstracts, Embase, Index Copernicus, EBSCO, African Index Medicus, JournalSeek, Journal Citation Reports/Science Edition, Directory of Open Access Journals (DOAJ), African Journal Online, Bioline International, Open-J-Gate and Pharmacy Abstracts

\section{INTRODUCTION}

Liver disease is a serious problem in developing countries and a cause of morbidity and mortality throughout the world. Liver ailments are frequently caused by hepatitis A, B and C viruses, carbon tetrachloride (CCl4), high doses of paracetamol, thioacetamide (TAA) and certain chemotherapeutic agents etc. [1]. It has been estimated in recent reports that $10 \%$ of world population is affected with liver diseases including hepatitis, alcoholic steatosis, fibrosis, 
liver cirrhosis and hepatocellular carcinoma. Morbidity and mortality resulting from liver diseases is a major public health problem worldwide [2]. The management of liver diseases is still a challenge to modern medicine. The drugs available for the treatment of liver diseases are only corticosteroids and immunosuppressive agents which exert several serious adverse effects. This has led to increased dependency on complementary and alternative medicine, especially herbal/plant-based medicines. Medicinal plants play a vital role in the management of liver disorder in the developing world for primary health care because they are inexpensive, possessing minimal or no side effect and easy availability in nature [3]. The hepatoprotective effects of several medicinal plants such as Leptadenia reticulata stem [4], Suaeda fructocosa roots [5], Cleome viscose leaves [6], Zingiber officinale and Piprum nigrum have been evaluated in some previous reports [7].

Alhagi marjoram Boiss., belong to the family Leguminosae or Fabaceae, commonly known as camel thorn or Persian manna plan. This is native to the geographical areas extending from the temperate and tropical Eurasia and the Middle East Pakistan, India, Bangladesh, Iran, Iraq, Jordan, Israel, Kuwait, Lebanon, Cyprus, Turkey, Turkmenistan, Uzbekistan and Russia [8]. It is widely distributed in Cholistan Desert of Bahawalpur (Pakistan) and traditionally used by local inhabitants in various disorders like hepatitis, jaundice, stomatitis, kidney stones, urinary retention, flatulence and piles [9].

Literature search reveals that Alhagi marjoram is commonly prescribed in folk medicine as an antiasthmatic, aphrodisiac, antipyretic, appetizer, anti-rheumatic, diuretic, expectorant and laxative [10]. Alkaloids, flavonoids and fatty acids are the major active constituents of this genus $[11,12]$. Six main flavonoid glycosides such as kaempferol, chrysoeriol, isorhamnetin, chrysoeriol-7-O-xylosoid, kaempferol-3galactorhamnoside and isorhamnetin 3-O- $\beta-D-$ apio-furanosyl (1-2) $\beta$-D-galactopyranoside have been isolated from the ethanol extract of $A$. maurorum [13].

No scientific validation has been done on the whole plant materials of $A$. maurorum as a hepatoprotective agent until now. Therefore, the present study was aimed to evaluate its hepatoprotective activity against paracetamolinduced toxicity in experimental rabbits.

\section{EXPERIMENTAL}

\section{Plant collection and identification}

The plant was collected from Cholistan Desert of Bahawalpur, Pakistan and the plant material was identified and authenticated by Dr. Shazia Anjum, Director, Cholistan Institute of Desert Studies (CIDS), The Islamia University of Bahawalpur. A specimen (3428/CIDS/IUB) deposited in the Herbarium of CIDS, The Islamia University of Bahawalpur, Pakistan.

\section{Extract preparation}

The authenticated shade-dried whole plant of $A$. maurorum approximately $(1000 \mathrm{~g})$, was powdered to coarse particle size no. 40. The plant material was soaked in $3 \mathrm{~L}$ of $70 \%$ aqueous-ethanol for $72 \mathrm{~h}$ with occasional shaking and stirring in $5 \mathrm{~L}$ beaker. The extracts were separated from the residues by filtering through several layers of muslin cloth for coarse filtration and then through Whatman No. 1 filter paper. The residues were extracted twice with the same fresh solvent and all extracts were then combined. These filtered extracts were concentrated and solvents were evaporated under reduced pressure at $40{ }^{\circ} \mathrm{C}$, using a rotary evaporator (EYELA, CA-1111, Rikakikai Company Limited Tokyo, Japan). The dried crude concentrated extracts were weighed to calculate the percentage yield and stored in a refrigerator $\left(-8^{\circ} \mathrm{C}\right)$, until used for analyses.

\section{Chemicals}

Ethanol, distilled water, paracetamol, diagnostic kits (TB, SGPT, SGOT and ALP) by Human (Germany), xylene, paraffin wax, sodium hydroxide, sodium chloride, aluminum chloride, potassium hydroxide, benzene, ether, sulphuric acid, hydrochloric acid, potassium iodide, mercuric chloride, potassium bromide, eosin, hematoxylin and canada balsam. These chemicals were purchased from the Merck, Germany. Silymarin and pentothal sodium was obtained from the Abbott laboratories, Pakistan. All of the above mentioned chemicals were of analytical grade.

\section{Animals}

Healthy adult rabbits of (1000 - $1200 \mathrm{gm})$ were housed in cages with free access to standard rodent chow diet and water ad libitum and acclimatized to the surroundings for one week prior to the experiment. Animals were harbored on a light/dark cycle $(12 / 12 \mathrm{~h})$ at a constant 
temperature $\left(25 \pm 3^{\circ} \mathrm{C}\right.$ ) and relative humidity (50 $\pm 20 \%$ ).

\section{Hepatoprotective activity}

In the dose-response experiment, rabbits were randomly assigned into 5 groups of 6 individuals each. Group I: Animals (+ve control) were administered $1 \mathrm{~mL}$ distill water p. o, for 7 days. Group II: Animals (negative control) were administered $1 \mathrm{~mL}$ distilled water p. o. for 7 days. Group III: Animals were administered silymarin $50 \mathrm{mg} / \mathrm{kg}$ p.o, for 7 days. Group-IV: Animals were administered $70 \%$ ethanol extract at 250 $\mathrm{mg} / \mathrm{kg} \mathrm{p}$. o, for 7 days. Group V: Animals were administered with $70 \%$ ethanol extract 500 $\mathrm{mg} / \mathrm{kg}$ p.o. for 7 days. Paracetamol (PCM $2 \mathrm{~g}$ ) was administered orally on day 8th to each group except group 1 in divided doses of $400 \mathrm{mg} / \mathrm{kg}$ at $0,6,12,18$ and $24 \mathrm{~h}$. The animals were observed for $24 \mathrm{~h}$ after the PCM induction. The rabbits were sacrificed under mild ether anesthesia. Blood samples were collected by heart puncture for evaluating serum biochemical parameters like SGOT, SGPT, ALP and TB [14]. The liver samples were dissected out, washed with normal saline and preserved it in $10 \%$ formalin for histopathological studies to evaluate microscopically the details of hepatic architecture in each group [15].

\section{Histopathological examination}

A section of the liver was collected and immediately fixed in $10 \%$ formalin, and then dehydration in ascending grades of alcohol (ethanol) of 70, 80 and $95 \%$ and absolute alcohol for 2 changes each. The tissues were cleared in xylene and embedded in paraffin wax. Serial section of 5-6 microns in thickness were obtained using rotary microtome and stained with hematoxylin and eosin. The stained sections were examined under microscope for analyzing any changes in the architecture of the liver tissue due to paracetamol challenge and improved liver architecture due to pre-treatment with test extracts and standard drug [15].

\section{Phytochemical screening}

The extract of $A$. maurorum was screened for the presence of carbohydrate, alkaloids, triterpenoids, saponins, phenols, sterols and flavonoids by following standard procedures [16].

\section{Statistical analysis}

Results were expressed as Mean \pm SEM, $(n=6)$. Statistical analyses were performed with one way analysis of variance (ANOVA) followed by tukey's multiple comparison test by using Graph Pad Prism Software. $P<0.05$ was considered to be statistically significant.

\section{RESULTS}

\section{Phytochemical profile}

The extract of $A$. maurorum was positive for alkaloids, saponins, tannins, triterpinoids and flavonoids.

\section{Hepatoprotective activity}

A significant increase in serum SGPT, SGOT, ALP and total bilirubin level was observed in paracetamol (2 gm/kg s. c.) intoxicated rabbits. Pretreatment with $A$. maurorum $(250 \mathrm{mg} / \mathrm{kg}$ p.o.) for 7 days decreased the above parameters significantly $(p<0.01)$ while pretreatment with $A$. maurorum (500 mg/kg p.o.) for 7 days produced maximum reduction in liver enzymes and considered statistically more significant $(p<$ 0.001 ). The hepatoprotective effect at dose of $500 \mathrm{mg} / \mathrm{kg}$ was almost comparable to standard drug silymarin (Table 1).

Table 1: Effect of Alhagi maurorum on liver enzymes in paracetamol induced hepatotoxicity

\begin{tabular}{llcccc}
\hline Group & Treatment & SGPT (IU/L) & $\begin{array}{c}\text { SGOT } \\
\text { (IU/L) }\end{array}$ & $\begin{array}{c}\text { ALP } \\
\text { (IU/L) }\end{array}$ & Total bilirubin (mg/dL) \\
\hline I & Normal & $70.5 \pm 1.88$ & $71.1 \pm 1.31$ & $190 \pm 2.66$ & $0.71 \pm 0.05$ \\
II & Paracetamol & $145 \pm 10.47$ & $128.8 \pm 1.98$ & $305 \pm 2.12$ & $1.29 \pm 0.18$ \\
III & Sylimarin & $94 \pm 5.41^{* * *}$ & $83.8 \pm 3.37^{* *}$ & $270 \pm 3.55^{* * *}$ & $0.62 \pm 0.03^{* * *}$ \\
IV & $\begin{array}{l}\text { Alhagi maurorum } \\
\text { 250 mg/kg }\end{array}$ & $108.3 \pm 5.72^{*}$ & $99.17 \pm 1.9^{* * *}$ & $286 \pm 5.20^{* *}$ & $0.98 \pm 0.03^{*}$ \\
V & $\begin{array}{llll}\text { Alhagi maurorum } 500 \\
\text { mg/kg }\end{array}$ & $99.5 \pm 5.65^{* *}$ & $98.33 \pm 2.24^{* *}$ & $269 \pm 1.89^{* * *}$ & $0.90 \pm 0.03^{* * *}$
\end{tabular}

${ }^{*} p<0.01,{ }^{* *} p<0.001$ compared to paracetamol group (one-way ANOVA followed by Tukey's multiple comparison tests); values are mean $\pm \operatorname{SEM}(n=6)$ 


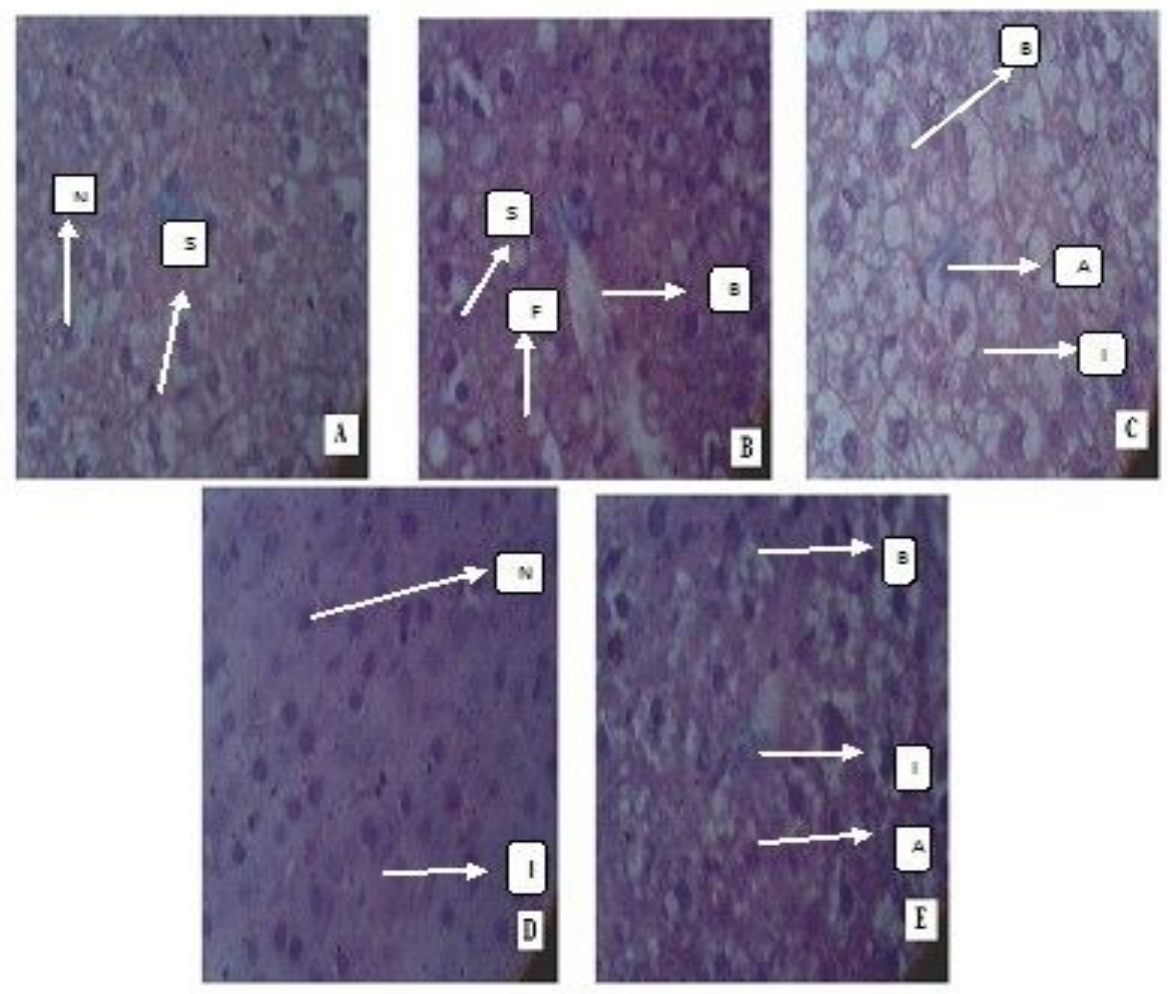

Fig 1: Photomicrography of liver sections in paracetamol induced hepatotoxicity in rabbits. A (Liver architecture of Normal); B: (Liver architecture of paracetamol treatment $+50 \mathrm{mg} / \mathrm{kg}$ Silymarin treatment); C: (Liver architecture of paracetamol treatment); D: Liver architecture paracetamol treatment $+500 \mathrm{mg} / \mathrm{kg}$ of Alhagi maurorum; and E: (Liver architecture paracetamol treatment $+250 \mathrm{mg} / \mathrm{kg}$ of Alhagi maurorum). Key: ( $N=$ nucleus, $S=$ sinusoid, $B$ = ballooning-degeneration, $F$ =fibrosis, $I=$ inflammation and $A$ = apoptosis)

\section{Histopathological features}

Histopathological examination of liver sections of normal rabbits showed normal hepatic cells with cytoplasm and nucleus whereas paracetamoltreated group showed various degree of fatty degeneration like ballooning of hepatocytes, infiltration of lymphocytes and the loss of cellular boundaries. Administration of $A$. maurorum at dose of $500 \mathrm{mg} / \mathrm{kg}$ significantly normalized these defects in the histological architecture of the liver (Figure 1).

\section{DISCUSSION}

The current study was designed to evaluate the hepatoprotective potential of the $A$. maurorum. This medicinal plant of Bahawalpur Cholistan desert has been reported to possess hepatoprotective effects in some previous reports. Its hepatoprotective activity of aerial parts in ethanol extract was evaluated against carbon tetrachloride intoxicated Wistar albino rats [17].

Paracetamol is generally used as an analgesic and antipyretic drug [18]. When taken in overdose $(200 \mathrm{mg} / \mathrm{kg})$, it produces potent hepatotoxicity, therefore it is widely used as a hepatotoxicant in experimental animals [19]. SGPT, SGOT, ALP and serum bilirubin level are commonly used biochemical parameters to evaluate liver injury. On induction of paracetamol hepatotoxicity, the SGPT, SGOT, ALP and bilirubin levels increase in the circulation because they are cytoplasmic in location and released into circulation after cellular damage [18]. The elevated level of these entire marker enzymes observed in the group II, paracetamol treated rabbits, corresponded to the extensive liver damage induced by toxin in our study. The levels of these biomarkers in pre-treated animals with $A$. maurorum $(500 \mathrm{mg} / \mathrm{kg}$ ) were found to be lower than the paracetamol intoxicated group indicating that this dose can protects the paracetamol induced hepatic damage. $A$. maurorum possesses flavonoids and tannins which were confirmed by phytochemical analysis of the extract and these both groups are well recognized for their hepatoprotective action. Saponins, alkaloids, flavonoids and triterpenoids are phytochemical constituents of $A$. maurorum possessing antioxidant, free radical scavenging ability and inhibition of lipid peroxidation [20,21]. Silymarin isolated from Silybum marianum is a well-known hepatoprotective compound and 
shown to have a protective effect on plasma membrane of hepatocytes and possesses multiple inhibitory effects against different hepatotoxic agents. The antioxidant effects and cell regenerating functions of silymarin involved protein synthesis and this was considered as most important actions of silymarin. The hepatoprotective activity observed in the present study may be due to the protective effect of $A$. maurorum on the plasma membrane of the hepatocytes or to cell regenerating function similar to that of silymarin, the reference drug used in the study [22].

The histopathological findings reveal that $A$. maurorum extract showed excellent protection on liver architecture, almost to the level of the silymarin-treated groups, validating its hepatoprotective effects in the experimental animal.

\section{CONCLUSION}

The findings of this study indicate that the aqueous-ethanol extract of $A$. maurorum at a dose of $500 \mathrm{mg} / \mathrm{kg}$ exhibits significant hepatoprotective activity by reducing elevated levels of biochemical enzymes. Further studies are required to explore the active principle responsible for this hepatoprotective activity.

\section{ACKNOWLEDGEMENT}

The authors are thankful to the Dean and Chairman of Faculty of Pharmacy \& Alternative Medicine, The Islamia University of Bahawalpur for providing laboratory resources and financial assistance to conduct this research work.

\section{REFERENCES}

1. Saleem TS, Chetty SM, Ramkanth S, Rajan VST, Kumar KM, Gauthaman K. Hepatoprotective herbs: A review. Int J Res Pharma Sci 2010; 1: 1-5.

2. Zhang $A$, Sun $H$, Wang $X$. Recent advances in natural products from plants for the treatment of liver diseases. Eur J Med Chem 2013; 63: 570-577.

3. Sheetal V, Singh SP. Current and future status of herbal medicine. Vet World 2008; 1: 347-350.

4. Amit KN, Abhinav A, Varsha K. Hepatoprotective activity of Leptadenia reticulate stem in carbon tetrachlorideinduced hepatotoxicity in rats. Indian J Pharmacol 2011; 43: 254-257.

5. Ur Rehman J, Us Saqib N, Akhtar N, Jamshaid M, Asif $H M$, Sultana S, Ur Rehman R. Hepatoprotective activity of aqueous-methanolic extract of Suaeda fruticosa in paracetamol-induced hepatotoxicity in rabbits. Bang J Pharmacol 2013; 8: 378-381.
6. Gupta NK, Dixit VK. Evaluation of hepatoprotective activity of Cleome viscosa Linn. extract. Indian J Pharmacol 2009; 41: 36-40.

7. Jamil MS, Mahmood Z, Saeed A, Jamil A, Usmanghani $K$, Asif HM, Rohi M. Efficacy of herbal coded Hepcon on drug induced hepatitis in experimental animals through histopathological and biochemical analysis. Pak J Pharm Sci 2013; 26: 991-997.

8. Ghazanfar S.A. Handbook of Arabian Medicinal Plants. CRC Press, 1994; $p 35$.

9. Ahmad Sl, Ahmad M, Saleem A Jabbar, Isar-ur-Rehman S, Saeed-ul-Hassan KS, Akhtar and MI Choudhary. Secondary metabolites from Alhagi maurorum. J Chem Soc Pak 2009; 931: 960-963

10. Pashayi Fakhri KP, Adelzadeh P. Pharmacology and Medicinal Aspects of Plants listed in Holey Quran; Alhagi (Alhagi maurorum) Bull. Env. Pharmacol. Life Sci 2013; 2: 19-22.

11. Goudah A, Mouneir SM, Shim JH, Abd El-Aty AM. Influence of endotoxin induced fever on the pharmacokinetics of intramuscularly administered cefepime in rabbits. $J$ Vet Sci. 2006; 7:151-155.

12. Awaad AAS, Maitland DJ, Soliman GA. Antiulcerogenic activity of Alhagi maurorum. Pharma Biol 2006; 44: 292-296.

13. Marashdah MS, Mudawi BM, Al-Hazimi HM, Abdallah MA. New aliphatic ketone and new aliphatic ester from the roots of Alhagi maurorum medik. J Saudi Chem Soc 2006; 10: 509-514.

14. Huang B, Ban X, He J, Tong J, Tian J, and Wang Y. Hepatoprotective and antioxidant activity of ethanolic extracts of Edible lotus (Nelumbonucifera Gaertn.) leaves. Food Chem 2010; 120: 873-78.

15. Luna LG. Manual of Histology and Staining methods of Armed Forces Institute of Pathology. 3rd ed. New York: McGraw Hill Book Co; 1986.

16. Trease GE, Evans WL. Pharmacognosy. 16th edn. London: Bailliere Tindall Ltd; 2009.

17. Alqasoumi SI, Al-Rehaily AJ, Abdulmalik MA, Maged, and Abdel-Kade S. Evaluation hepatoprotective effect of Ephedra foliate, Alhagi maurorum, Capsella bursapastoris and Hibiscus sabdariffa experimentally induced liver injury in Rats, Natur Prod Sci 2008; 14: 95-99.

18. Parmar SR, Vashrambhai PH, Kalia K. Hepatoprotective activity of some plants extract against paracetamol induced hepatotoxicity in rats. $J$ herb med toxicol 2010; 4: 101-106.

19. Daly FF, Fountain JS, Murray L, Graudins A, Buckley NA. "Guidelines for the management of paracetamol poisoning in Australia and New Zealand-explanation and elaboration. A consensus statement from clinical toxicologists consulting to the Australasian poisons information centres". Med J Aus 2008; 188 (5): 296301.

20. Faure $M$, Lissi E, Torres $R$, Vidella LA. Antioxidant activity of liginin and flavonoids. Phytochem 1990; 29: 3773-3775.

Trop J Pharm Res, June 2015; 14(6): 1033 
Rehman et al

21. Jin X, Qian J, Lu Y. The role of hepatoprotective effect of a flavonoid-rich extract of Salvia plebeia R.Br. on carbon tetrachloride induced acute hepatic injury in mice. J Med Plant. Res 2011; 5(9): 1558-1563
22. Bagban IM, Roy SP, Chaudhary A, Das SK, Gohil KJ, Bhandari KK. Hepatoprotective activity of the methanolic extract of Fagonia indica Burm in carbon tetrachloride-induced hepatotoxicity in albino rats. Asian Pacif J Trop Biomed. 2012; S1457-S1460. 